\title{
ERRATUM
}

\section{ON NON-SEPARATED ZERO SEQUENCES OF SOLUTIONS OF A LINEAR DIFFERENTIAL EQUATION - ERRATUM}

\author{
(first published online 24 November 2021)
}

The name of one of the authors was given incorrectly in the above-mentioned article [1]. Jianren R. Long should have been Jianren Long. This has been corrected in the original manuscript now.

The publishers apologise for this error.

\section{Reference}

1. Chyzhykov, I., \& Long, J. (2021). On non-separated zero sequences of solutions of a linear differential equation. Proceedings of the Edinburgh Mathematical Society, 64(2), 247-261. doi:10.1017/S0013091521000122 